\title{
PENGARUH BEBAS-HUJAN SETELAH APLIKASI TERHADAP EFIKASI GLIFOSAT PADA GULMA DI LAHAN KELAPA SAWIT
}

\author{
Riwandi Aritonang \\ Program Studi Agroteknologi \\ Fakultas Pertanian, Universitas Sumatera Utara, Medan 20155, Indonesia \\ riwandi06@gmail.com
}

\begin{abstract}
The objective of this research was to study the efficacy of herbicide products with active ingredients of glyphosate on some rain-free period after application to weeds in oil palm plantations. The research were are design arranged in split-plot design with two factors and three replications. The main factor is glyphosate herbicide (Crucial 700; Crucial 550; Roundup Power Max; Roundup Biosorb; Kleenup). And the second factor is period rainfree after aplications $(0.5 ; 1.0 ; 2.0 ; 4,0 ;$ and no rain). The results of this study showed that all glyphosate-based herbicides required rain-free period after application more than where the efficacy four hours. The highest damage (80\%) of weed on rain free time after 12 hours.
\end{abstract}

\begin{abstract}
Abstrak
Penelitian ini bertujuan mengetahui efikasi produk herbisida berbahan aktif glifosat pada beberapa waktu bebas-hujan setelah aplikasi terhadap gulma di perkebunan kelapa sawit. Penelitian ini menggunakan Rancangan Petak Terpisah dengan 2 faktor perlakuan dan tiga ulangan. Faktor utama adalah herbisida glifosat (Crucial 700, Crucial 550, Roundup Power Max, Roundup Biosorb, Kleenup) dan faktor kedua adalah periode bebas-hujan yang terdiri dari (0.5 JSA, 1.0 JSA, 2.0 JSA, 4.0 JSA dan Tanpa Penghujanan). Hasil penelitian menunjukkan semua herbisida berbahan aktif glifosat yang diujikan membutuhkan waktubebas-hujan setelah aplikasi diatas empat jam. Pada waktu-bebas-hujan setelah 12 jam setelah aplikasi (JSA) menghasilkan kerusakan gulma sebesar $80 \%$.
\end{abstract}

Kata Kunci : herbisida glifosat, periode bebas hujan, efikasi

\section{Pendahuluan}

Di Indonesia, umumnya banyak ditemui perkebunan sawit, dan daerahnya umumnya memiliki curah hujan yang tinggi, seperti di Sumatera Utara, yakni berkisar antara 2.000 $4.000 \mathrm{~mm}$ per tahun, dengan musim kemarau jatuh pada bulan Juni sampai September, tetapi masih ada hujan turun yang menyediakan kebutuhan air bagi tanaman (Fauzi, 2014). Musim penghujan di Indonesia terjadi antara bulan September sampai dengan bulan Maret. Curah hujan merupakan unsur penting yang berpengaruh pada produksi pertanian dan ketahanan pangan. Curah hujan berkorelasi tinggi dengan komponen hasil tanaman. Di sisi lain, pada musim hujan akan timbul masalah,yaitu peningkatan kuantitas gulma (National Academy of Sciences, 1968; Santoso, 1992). 
Keberadaan gulma menjadi masalah karena membutuhkan tenaga, biaya, dan waktu yang terus menerus untuk mengendalikannya. Gulma merupakan salah satu masalah utama dalam budidaya tanaman perkebunan kelapa sawit. Secara umum penurunan hasil produksi tanaman budidaya kelapa sawit akibat kehadiran gulma dapat mencapai $20-80 \%$ bila gulma tidak dikendalikan. Salah satu metode pengendalian, gulma yang umum dan utama pada perkebunan kelapa sawit adalah pengendalian secara kimia dengan menggunakan herbisida, karena cara ini lebih efektif, efisien, hemat tenaga, biaya dan waktu. Pengendalian secara kimia di lakukan empat bulan sekali atau tiga kali dalam setahun. (Moenandir,1985).

Glifosat, merupakan herbisida yang paling umum digunakan di perkebunan, khususnya kelapa sawit. Glifosat, herbisida terpenting di dunia saat ini, adalah herbisida dengan cara kerjanya yaitu translokasi, menghambat kerja enzim 5-enolpyruvylshikimate-3-phosphate synthase (EPSPS), enzim yang terlibat dalam sintesa tiga asam amino (Purba, 2009). Herbisida ini diabsorbsi oleh daun dan ditranslokasikan dalam tumbuhan yang berlangsung secara sistemik, yaitu melalui jaringan hidup dan pembuluh utama floem menuju ke jaringan meristem (Sriyani, 2016).

Efikasi glifosat dapat menurun secara drastis apabila herbisida ini diaplikasi ke tajuk gulma pada kondisi musim hujan herbisida akan berkurang efektivitasnya karena dapat tercuci oleh air hujan yang turun setelah aplikasi (National Academy of Sciences, 1968). Ketepatan waktu aplikasi herbisida menjadi salah satu hal terpenting dalam pengendalian gulma. Kondisi cuaca yang mengindikasikan akan turun hujan lebih baik dihindari, karena akan terjadi pencucian yang mengurangi efektivitas herbisida (Reddy dan Singh,1992).

\section{Bahan dan Metode}

Penelitian ini dilaksanakan pada bulan Desember 2017 s/d Maret 2018 di areal Perkebunan Kelapa Sawit PTPN II Kebun Tanjung Garbus, tahun tanam 2014 dengan jumlah tanaman 143/ha. Pada lokasi percobaan rata-rata curah hujan sekitar 2000-2500 mL per tahun.

Pembuatan petak percobaan dilakukan dengan menentukan plot diantara piringan kelapa sawit dengan memperhatikan kondisi gulma yang relatif homogen dengan ukuran plot $3 \mathrm{~m} \mathrm{x}$ $2,4 \mathrm{~m}$.

Penelitian menggunakan rancangan petak terpisah dimana petak utama (main plot) adalah formulasi herbisida yang terdiri atas lima jenis produk berbahan aktif glifosat Crucial 700 SL 1,33 L/ha (H1), Crucial 550 SL 1,7 L/ha (H2), Roundup Biosorb 480 SL 1,33 L/ha (H3), Roundup Biosorb 2 L/ha (H4), Kleenup 480 SL 2 L/ha (H5) dan tanpa herbisida, sedangkan anak petak (sub-plot) terdiri dari 5 taraf waktu bebas-hujan yaitu 0.5 (B1), 1.0 (B2), 2.0 (B3), 4.0 (B4) jam setelah aplikasi (JSA) dan tanpa hujan (B5), Untuk hasil pengendalian secara visual data diolah dengan Anova dan plot tanpa perlakuan dikeluarkan dari Anova. 
Data dianalisis dengan ANOVA, kemudian dilanjutkan ke uji Duncan'sMultiple Range Test (DMRT) pada taraf 5\%. Parameter yang di amati antara lain : Mortalitas, bobot kering dan Re-Growth.

\section{Hasil dan Pembahasan}

\section{Mortalitas (Tingkat Kematian Gulma)}

Hasil sidik ragam menunjukkan bahwa pengaruh waktu bebas-hujan berpengaruh nyata terhadap parameter kematian gulma(mortalitas) pada pengamatan 7-28 HSA, sedangkan perlakuan herbisida menunjukkan pengaruh nyata terhadap parameter kematian gulma (mortalitas) pada umur pengamatan 7, 14 dan 21 HSA dan interaksi antara herbisida dan waktu-bebas-hujan berpengaruh nyata terhadap kematian gulma (mortalitas) pada umur pengamatan 21 HSA.

Tabel 1.Persentase kematian gulma dengan penyemprotan herbisida berbahan aktif glifosat pada berbagai waktu bebas-hujan pengamatan 7-28 HSA.

\begin{tabular}{|c|c|c|c|c|c|c|c|}
\hline \multirow[t]{3}{*}{ HSA } & \multirow{3}{*}{$\begin{array}{l}\text { Produk } \\
\text { Herbisida }\end{array}$} & \multicolumn{5}{|c|}{ Perlakuan waktu-bebas-hujan } & \multirow[t]{2}{*}{ Rataan } \\
\hline & & \multirow[t]{2}{*}{$\begin{array}{l}\text { B1 }(0,5 \\
\text { JSA) } \\
\end{array}$} & B2(1 JSA) & B3(2 JSA) & B4(4 JSA) & B5(12JSA) & \\
\hline & & & & \multicolumn{4}{|c|}{ 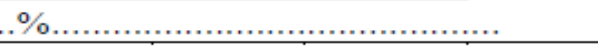 } \\
\hline \multirow{6}{*}{7} & H1 (Crucial 700) & 0 & 10 & 2 & 5 & 40 & $11,4 \mathrm{~b}$ \\
\hline & $\mathrm{H} 2$ (Crucial 550) & 0 & 7 & 5 & 8 & 23 & $8,6 \mathrm{~b}$ \\
\hline & H3 (Roundup Power Max) & 0 & 3 & 12 & 18 & 22 & $11 \mathrm{~b}$ \\
\hline & H4 (Roundup Biosorb) & 0 & 3 & 17 & 18 & 40 & $15,6 \mathrm{ab}$ \\
\hline & H5 (Kleenup) & 0 & 15 & 23 & 22 & 55 & $23 \mathrm{a}$ \\
\hline & Rataan & $0 \mathrm{~d}$ & $7,6 \mathrm{c}$ & $11,8 \mathrm{bc}$ & $14,2 \mathrm{~b}$ & $36 \mathrm{a}$ & \\
\hline \multirow{6}{*}{14} & H1 (Crucial 700) & 0 & 30 & 10 & 17 & 80 & $27,4 \mathrm{~b}$ \\
\hline & H2 (Crucial 550) & 0 & 10 & 17 & 20 & 83 & $26 \mathrm{c}$ \\
\hline & H3 (Roundup Power Max) & 0 & 10 & 13 & 60 & 83 & $33,2 \mathrm{~b}$ \\
\hline & H4 (Roundup Biosorb) & 0 & 17 & 50 & 70 & 80 & $43,4 a$ \\
\hline & H5 (Kleenup) & 0 & .23 & 50 & 70 & 93 & $47,2 \mathrm{a}$ \\
\hline & Rataan & $0 \mathrm{c}$ & $18 \mathrm{~b}$ & $28 \mathrm{~b}$ & $47,4 \mathrm{ab}$ & $83,8 \mathrm{a}$ & \\
\hline \multirow{6}{*}{21} & H1 (Crucial 700) & $5 \mathrm{f}$ & $22 \mathrm{de}$ & $20 \mathrm{e}$ & $13 \mathrm{e}$ & $75 \mathrm{ab}$ & 27 \\
\hline & H2 (Crucial 550) & $5 \mathrm{f}$ & $17 \mathrm{e}$ & 40 cde & $35 \mathrm{~cd}$ & 87 a & 36,8 \\
\hline & H3 (Roundup Power Max) & $5 \mathrm{f}$ & $18 \mathrm{e}$ & $25 \mathrm{e}$ & $25 \mathrm{e}$ & 83 a & 31,2 \\
\hline & H4 (Roundup Biosorb) & $3 \mathrm{f}$ & $36 \mathrm{de}$ & 42 a-d & $75 \mathrm{ab}$ & 88 a & 48,8 \\
\hline & H5 (Kleenup) & $4 \mathrm{f}$ & $30 \mathrm{e}$ & $72 \mathrm{ab}$ & $72 \mathrm{ab}$ & $95 \mathrm{a}$ & 54,6 \\
\hline & Rataan & 4,4 & 24,6 & 39,8 & 44 & 85,6 & \\
\hline \multirow{6}{*}{28} & H1 (Crucial 700) & 5 & 23 & 18 & 12 & 73 & 26,2 \\
\hline & H2 (Crucial 550) & 5 & 20 & 48 & 37 & 75 & 37 \\
\hline & H3 (Roundup Power Max) & 5 & 40 & 37 & 37 & 80 & 39,8 \\
\hline & H4 (Roundup Biosorb) & 5 & 20 & 32 & 78 & 93 & 45,6 \\
\hline & H5 (Kleenup) & 5 & 23 & 23 & 78 & 65 & 38,8 \\
\hline & Rataan & $5 \mathrm{~d}$ & $25,2 \mathrm{bc}$ & $31,6 \mathrm{abc}$ & $48,4 \mathrm{ab}$ & $77,2 \mathrm{a}$ & \\
\hline
\end{tabular}

Keterangan :Angka yang diikuti oleh huruf, kolom dan umur pengamatan yang sama menunjukkan pengaruh berbeda tidak nyata pada uji jarak Duncan pada taraf $\alpha=5 \%$.

Rendahnya kerusakan gulma yang terjadi pada waktu-bebas-hujan 0,5 JSA disebabkan oleh pencucian oleh air hujan yang turun selang penyemprotan sehingga menyebabkan herbisida 
glifosat kehilangan efektifitas. Glifosat membutuhkan waktu untuk bisa berpenetrasi kedalam tubuh tumbuhan.

Interaksi antara herbisida glifosat dengan waktu bebas-hujan berpengaruh nyata pada umur pengamatan $21 \mathrm{HSA}$, interaksi disebabkan oleh pengaruh bebas-hujan yang menyebabkan persentase kematian gulma pada setiap herbisida berbahan aktif glifosat berbeda-beda. Semakin lama waktu-bebas-hujan yang dilakukan semakin tinggi persentase kematian gulma yang dihasilkan oleh herbisida berbahan aktif gulma.

Pengaruh bebas-hujan dan berbagai herbisida terhadap kematian gulma (mortalitas) pada pengamatan 28 hari setelah aplikasi (HSA), menunjukkan pengaruh tidak nyata pada perlakuan herbisida, sedangkan pada perlakuan bebas-hujan menunjukkan pengaruh nyata pada parameter kerusakan gulma.

\section{Penurunan Persentase Bobot Kering dengan untreated}

Hasil sidik ragam menunjukkan bahwa perlakuan waktu-bebas-hujan,herbisida glifosat dan interaksi antara waktu-bebas-hujan dan herbisida menunjukkan pengaruh nyata terhadap bobot kering gulma.

Tabel 2. Bobot kering gulma dengan penyemprotan herbisida berbahan aktif glifosat pada berbagai waktu bebas-hujan dan persentase penurunan terhadap untreated (tanpa perlakuan).

\begin{tabular}{|c|c|c|c|}
\hline Perlakuan & Bobot kering & $\begin{array}{l}\text { bobot kering } \\
\text { untreated }\end{array}$ & $\begin{array}{l}\% \text { Penurunan } \\
\text { Bobot kering }\end{array}$ \\
\hline H1B1 (Crucial $700 \mathrm{SL}$ dengan 0.5 JSA) & 23,2 & 46,56 & 50,1 \\
\hline H1B2 (Crucial 700 SL dengan 1.0 JSA) & 11,1 & 46,56 & 76,2 \\
\hline H1B3 (Crucial 700 SL dengan 2.0 JSA) & 15,9 & 46,56 & 65,9 \\
\hline H1B4 (Crucial 700 SL dengan 4.0 JSA) & 14,9 & 46,56 & 68,1 \\
\hline H1B5 (Crucial 700 SL tanpa hujan) & 3,4 & 46,56 & 92,8 \\
\hline H2B1 (Crucial 550 SL dengan 0.5 JSA) & 18,0 & 46,56 & 61,3 \\
\hline H2B2 (Crucial 550 SL dengan 1.0 JSA) & 21,3 & 46,56 & 54,3 \\
\hline H2B3 (Crucial 550 SL dengan 2.0 JSA) & 7,5 & 46,56 & 83,9 \\
\hline H2B4 (Crucial 550 SL dengan 4.0 JSA) & 7,2 & 46,56 & 84,5 \\
\hline H2B5 (Crucial 550 SL tanpa hujan) & 0,0 & 46,56 & 100,0 \\
\hline H3B1 (Roundup Power Max dengan 0.5 JSA) & 41,7 & 46,56 & 10,4 \\
\hline H3B2 (Roundup Power Max dengan 1.0 JSA) & 11,5 & 46,56 & 75,3 \\
\hline H3B3 (Roundup Power Max dengan 2.0 JSA) & 20,2 & 46,56 & 56,7 \\
\hline H3B4 (Roundup Power Max dengan 4.0 JSA) & 16,6 & 46,56 & 64,4 \\
\hline H3B5 (Roundup Power Max tanpa hujan) & 5,9 & 46,56 & 87,3 \\
\hline H4B 1 (Roundup Biosorb dengan 0.5 JSA) & 33,2 & 46,56 & 28,6 \\
\hline H4B2 (Roundup Biosorb dengan 1.0 JSA) & 15,5 & 46,56 & 66,6 \\
\hline H4B3 (Roundup Biosorb dengan $2.0 \mathrm{JSA}$ ) & 13,4 & 46,56 & 71,2 \\
\hline H4B4 (Roundup Biosorb dengan 4.0 JSA) & 0,2 & 46,56 & 99,6 \\
\hline H4B5 (Roundup Biosorb tanpa hujan) & 0,6 & 46,56 & 98,7 \\
\hline H5B1 (Kleenup dengan 0.5 JSA) & 23,6 & 46,56 & $49, \mathrm{e}$ \\
\hline H5B2 (Kleenup dengan 1.0 JSA) & 6,2 & 46,56 & 86,6 \\
\hline H5B3 (Kleenup dengan 2.0 JSA) & 9,4 & 46,56 & 79,9 \\
\hline H5B4 (Kleenup dengan 4.0 JSA) & 11,0 & 46,56 & 76,3 \\
\hline H5B5 (Kleenup tanpa hujan) & 2,4 & 46,56 & 94,8 \\
\hline
\end{tabular}


Hasil pada Tabel 2, menunjukkan bahwa kelima herbisida (Crucial 700,Crucial 550, Roundup Power Max, Roundup Biosorb, dan Kleenup) menghasilkan bobot kering terendah dengan perlakuan B5 (12 JSA/tanpa hujan), sehingga menghasilkan penurunan persentase bobot kering tertinggi jika dibandingkan dengan bobot kering tanpa perlakuan (untreated), sedangkan penurunan persentase bobot kering terendah dihasilkan pada H3B1 (Roundup Power Max dengan penghujanan 0,5 JSA).

Penyemprotan herbisida glifosat dengan tanpa penghujanan menyebabkan efikasi yang dihasilkan oleh herbisida lebih tinggi sehingga menyebabkan kematian gulma lebih tinggi sementara jika terkena air hujan, efikasi yang dihasilkan berkurang sehingga meninggalkan gulma yang tetap hidup (survival). Namun pengambilan bobot kering dilakukan dengan cara membuat cuplikan $50 \mathrm{~cm} \times 50 \mathrm{~cm}$, sehingga terkadang pelemparan cuplikan pada plot terdapat pada bagian plot dengan kerapatan yang sedikit sehingga gulma yang terambil hanya sedikit atau spot yang terdapat gulma yang sudah mati dibandingkan yang hidup.

\section{Pertumbuhan Kembali (Re-Growth)}

Hasil sidik ragam menunjukkan bahwa perlakuan waktu-bebas-hujan berpengaruh nyata pada umur $60 \mathrm{HSA}$, sementara perlakuan herbisida menunjukkan pengaruh nyata pada umur 60 HSA. Interaksi antara perlakuan waktu-bebas-hujan dan herbisida tidak nyata terhadap pertumbuhan kembali gulma (re-growth).

Tabel 3. Pertumbuhan kembali (re-growth) gulma dengan penyemprotan herbisida berbahan aktif glifosat pada berbagai waktu bebas-hujan pengamatan 60-90 HSA.

\begin{tabular}{|c|c|c|c|c|c|c|c|}
\hline \multirow[t]{3}{*}{ HSA } & \multirow{3}{*}{$\begin{array}{l}\text { Produk } \\
\text { Herbisida }\end{array}$} & \multicolumn{5}{|c|}{ waktu-bebas-hujan } & \multirow[t]{3}{*}{ Rataan } \\
\hline & & $\mathrm{Bl}(0,5 \mathrm{JSA}$ & B2(1 JSA) & B3(2 JSA) & B4(4 JSA) & B5(12JSA) & \\
\hline & & \multicolumn{5}{|c|}{ n.w. } & \\
\hline \multirow{6}{*}{60} & H1 (Crucial 700) & $5 \mathrm{~b}$ & $87 \mathrm{a}$ & $73 \mathrm{a}$ & $75 \mathrm{a}$ & $77 \mathrm{a}$ & $63,4 \mathrm{a}$ \\
\hline & H2 (Crucial 550) & $5 \mathrm{~b}$ & $82 \mathrm{a}$ & 72 a & 72 a & $72 \mathrm{a}$ & $60,6 \mathrm{ab}$ \\
\hline & H3 (Roundup Power Max) & $0 \mathrm{c}$ & $60 \mathrm{a}$ & $78 \mathrm{a}$ & $75 \mathrm{a}$ & $85 \mathrm{a}$ & $59,6 \mathrm{ab}$ \\
\hline & H4 (Roundup Biosorb) & $0 \mathrm{c}$ & $72 \mathrm{a}$ & $62 \mathrm{a}$ & $58 \mathrm{a}$ & $73 \mathrm{a}$ & $53 \mathrm{~b}$ \\
\hline & H5 (Kleenup) & $0 \mathrm{c}$ & $82 \mathrm{a}$ & $78 \mathrm{a}$ & $82 \mathrm{a}$ & $72 \mathrm{a}$ & $62,8 \mathrm{a}$ \\
\hline & Rataan & $2 \mathrm{~b}$ & $76,6 \mathrm{a}$ & $72,6 \mathrm{a}$ & 72,4 a & $75,8 \mathrm{a}$ & \\
\hline \multirow{6}{*}{90} & H1 (Crucial 700) & 73 & 83 & 83 & 83 & 85 & 81 \\
\hline & H2 (Crucial 550) & 65 & 88 & 75 & 75 & 84 & 77 \\
\hline & H3 (Roundup Power Max) & 68 & 83 & 80 & 73 & 82 & 77 \\
\hline & H4 (Roundup Biosorb) & 78 & 87 & 78 & 82 & 60 & 77 \\
\hline & H5 (Kleenup) & 78 & 75 & 73 & 67 & 67 & 72 \\
\hline & Rataan & 72,4 & 83,2 & 77,8 & 76 & 75,6 & \\
\hline
\end{tabular}

Keterangan :Angka yang diikuti oleh huruf, kolom dan hari pengamatan yang sama menunjukkan pengaruh berbeda tidak nyata pada uji jarak Duncan pada taraf $\alpha=5 \%$. 
Pertumbuhan kembali gulma yang tertinggi dihasilkan pada perlakuan H1 (Crucial 700 SL) dan perlakuan H4 (Roundup Biosorb) dengan rataan pertumbuhan kembali gulma terendah. Pertumbuhan kembali gulma 60 menunjukkan interaksi nyata perlakuan herbisida dengan waktu-bebas-hujan. Pertumbuhan kembali gulma menunjukkan persentase yang berbedabeda setiap plotnya.

\section{Simpulan}

Pada bebas-hujan 0,5 jam setelah aplikasi (JSA), kelima herbisida menghasilkan kematian gulma (mortalitas) yaitu $5 \%$. Urutan efektifitas herbisida pada bebas-hujan mulai 1.0, 2.0,dan 4.0 jam setelah aplikasi adalah Roundup Power Max ; Crucial 550 SL ; Roundup Biosorb dan Kleen up. Pada perlakuan tanpa penghujanan, herbisida Roundup Bisosorb menghasilkan rataan kematian gulma tertinggi, Crucial 700 SL, Crucial 550 SL, Roundup Powermax 660 SL, Roundup Biosorb 486 SL dan herbisida Kleenup 480 SL membutuhkan waktu 12 jam setelah aplikasi untuk menghasilkan $80 \%$ kematian gulma.

\section{Referensi}

Moenandir. J. 2010. Ilmu Gulma. Universitas Brawijaya Press (UB Press), Malang.

National Academy of Sciences. 1968. Principles of Plant and Animal Pest Control (Volume 2: Weed Control). National Academy of Sciences. Washington DC.

Purba. E. 2009. Keanekaragaman Herbisida dalam Pengendalian Gulma Mengatasi Populasi Gulma Resisten dan Toleran herbisida. USU Press

Reddy dan Singh, 1992. Factors Affecting Toxicity, Absorption, and Translocation of Glyphosate in Redvine (Brunnichia ovata).J. Weed Technology. Volume 14: 457 462. Prasetyo, H dan S. Zaman.2016. Pengendalian Gulma Perkebunan Kelapa Sawit (Elaeis guineensis Jacq.) di Perkebunan Padang Halaban, Sumatera Utara.Bul.Agrohorti 4(1): 87-93

Sriyani, 2016. Pengelolaan Gulma dan Herbisida untuk Meningkatkan Produktivitas Lahan Pertanian Secara Berkelanjutan. Pidato Ilmiah Pengukuhan Guru Besar Bidang Pengelolaan Gulma dan Herbisida. Fakultas Pertanian, Universitas Lampung.

Santosa, E., S. Zaman, dan I. D. Puspitasari, 2009. Simpanan Biji Gulma dalam Tanah di Perkebunan Teh pada Berbagai Tahun Pangkas. J. Agron.Indonesia 37 (1) : 46 54 (2009). 